\title{
An Approach to Develop Network Course Based on Software Lifecycle and Its Implementation
}

\author{
Suxian Lin, Wen-an Tan, Yun Yang and Fujun Yang \\ Software Engineering Institute, Zhejiang Normal University, Jinhua 321004, P.R. China \\ linsuxian@126.com jk76@zjnu.cn yangyun662000@yahoo.com.cn yangfujun11@163.com
}

\begin{abstract}
The design of traditional network course is developed by its specialized teachers and technicians to achieve its teaching goal. This miniature network class might be called as one-off and non-renewable resource. Nowadays, along with the mature of computer component technology, the development of this manual workshop-like is obsolete. This paper discusses the development process of the network course based on the model of software lifecycle and a case study about the network course of Software Engineering. A reconfigurable network course has been developed to validate the proposed method according to the development method of software component engineering technology.
\end{abstract}

Keywords: Network course, Software engineering, Requirement analysis, Component technology, Reuse

\section{INTRODUCTION}

The appearance of network course is sure not accidental, accompanying with the popularization of Internet and the swift development towards wide band, high speed and multimedia. Since the plan of education information has started, network course has gradually mounted the modern education stage. When a project begins to implement, there is more or less blind and disorder. While everybody showed his or her "great achievements" in succession, many questions appeared, such as: network course is mostly incomplete; the interaction between teachers and students is unperfect; besides, once network course is formed, few would update it actively or update difficultly, which is lack of flexibility. In short, it's devoid of unified criterion, and the demand analysis work of network course is ignored. Further, it's limited in the development of former network course, which likes that one or two teacher invite some computer technicians to develop network course individually. It's not only a waste of money, but also a waste of precious time. In view of these questions, this paper proposes an engineering idea of software engineering to develop network course. As we all know, network course contains two factors according to its definition [1]: one is the teaching content which is organized by certain teaching goal and teaching strategy; the other is network teaching supporting environment (which can also be called as network course development platform). Network course is a kind of system engineering. We should spend more time in demand analysis. That is to say, it's possible to use some correlative network course development platforms which

Please use the following format when citing this chapter:

Lin, S., Tan, W-A., Yang, Y., Yang, F., 2007, in IFIP International Federation for Information Processing, Volume 255, Research and Practical Issues of Enterprise Information Systems II Volume 2, eds. L. Xu, Tjoa A., Chaudhry S. (Boston: Springer), pp. 993-1000. 
have already appeared to integrate the resource of network course by relying on simple operation. Achieving network course in the long-term benefits is more economical and effective. The following are the concrete contents which introduce the method and process for developing network course.

\section{A METHOD TO DEVELOP NETWORK COURSE}

The development of network course is a software engineering essentially [2]. It needs the conception of systematization and engineering. Videlicet, the producer can effectively deliver the qualified software product they need by considering every factor comprehensively, removing the disadvantageous environment, facing the actual economic situation, using the most suitable technology, neglecting the inessential defect. Referring to some models of software life cycle, this paper uses component technology to perfect the details, and monitors the system development from soup to nuts combining with the waterfall model.

Software engineering is a subject of developing high quality software in the promissory development circle. It is significant for guiding the development of network course. Referring to the development process, network course can be developed as following processes [3]: respectively named as "Definition phase", "Development phase", "Examination, payment and maintenance phase". Each phase works as follows.

\subsection{Definition Phase}

Definition phase includes feasibility study and demand analysis of network course. From the very beginning, feasibility analysis is devoted to defining problems. That is to say, it can be perspicuous about the user's basic problem which should be solved by computer, as well as the resources and funds [4]. As is known to everyone, "Modern Distance Education Engineering" is one of the six projects which belong to the Plan for Educational Revitalization to face the 21st Century. In January, 2000, after the notice of implementing new century network course construction project issued by High Education Department, this project is responded in nearly each school, and it surges a tide of making network course. However, along with the development of economy and the maturity of technology, and software engineering striking root in the hearts of the people day after day, people gradually realize that, when each department makes his own netwotk course, it consumes extremely huge in the physical and financial resource. Moreover, the completed network course is a kind of non-renewable resource which is often one-off and difficult to update, certainly it doesn't conform to the sustainable development strategy. So how to solve these problems, how to fully utilize the advantages of network which contain openness, sharing, interaction and extensibility, in order to design network course who is then owns universally, versatility, extensibility and renewability in certain domain. Therefore besides some relevant methodology and technology supporting, it requires the maker to normalize everything in its domain, to formulate the relative unification form and standard. Then on the basis of this, we do the feasibility reasoning and 
frame the initial plan of project development in order to guide the development of network course efficiently.

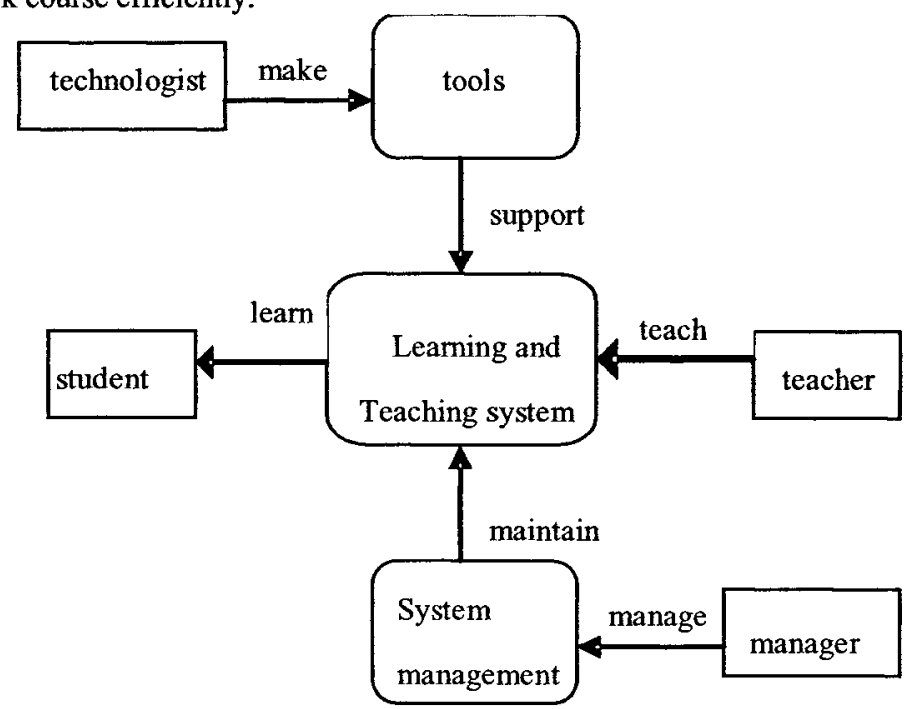

Figure 1. The Working Environment of Network Course

Next, the demand analysis of network course is done. Network course system consists of a series of modern teaching tools which support multi-educational model. The system mainly includes learning and teaching system (non-real-time/real-time), teaching resource edition system and management system. The relationship between them can be demonstrated by the top data flow diagram in Figure 1.

Among them, learning and teaching system includes operation system and supporting system, such as: course introduction, teaching (way of video), counseling $\mathrm{Q} / \mathrm{A}$, homework mark, testing and appraisal, academic exchange and discussion, virtual experiment and search engine, etc. as is showed in Figure 2. These subsystems mentioned in the preceding section can be implemented according to the standard of the ministry of education or going by the document which is canonical and certified by authority in certain domain. Here this paper uses the course of software engineering to discuss the analysis and the design.

Teaching resource edition system refers to the software development platform of making network course. It can be developed by oneself or by combining certain company [5], as Figure 3 shows. Some network course platform software has already appeared abroad, such as WebCT, Web-Course-in-a-Box, LearningSpace, etc. Now some components have either appeared in domestic, such as the class Dream Factory of Beijing Vellcom Technology Co., Ltd and ChinaEDU CPT2.2 in Beijing, they can easily integrate all resources. 


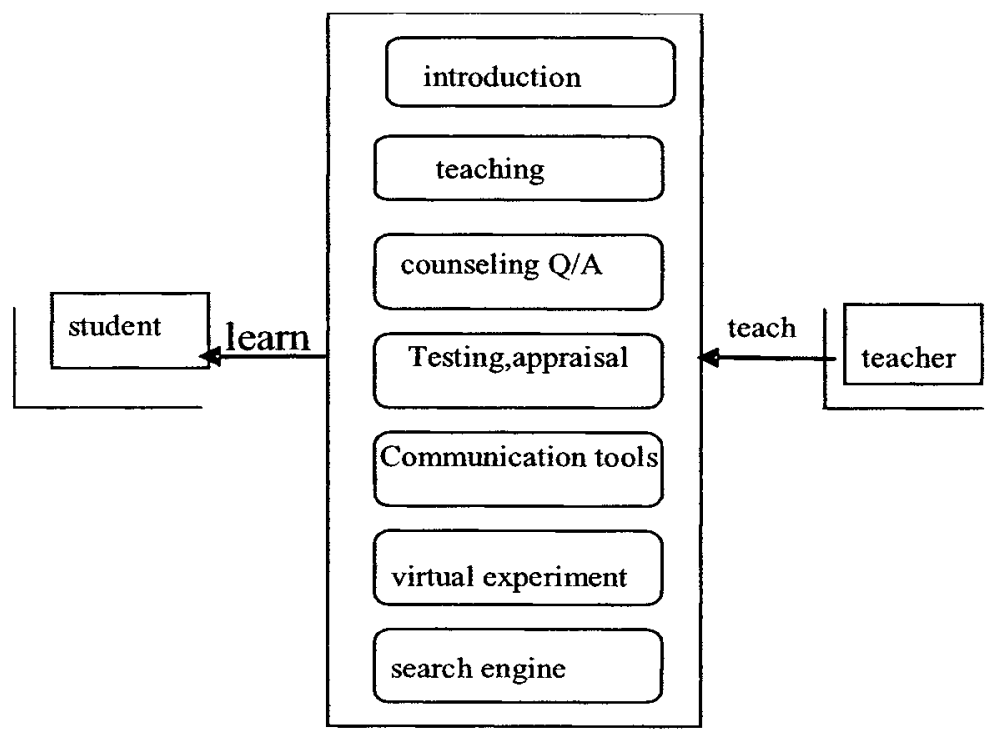

Figure 2. Learning System

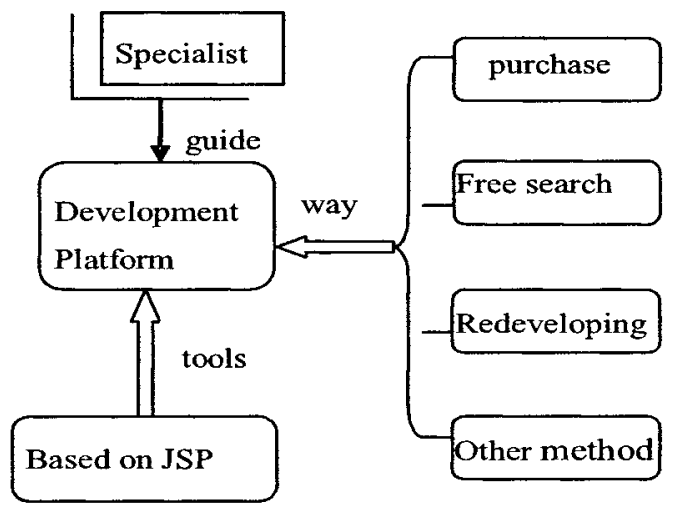

Figure 3. Manufacture Tools Structure

The daily management service must be explicit in the demand analysis phase. The daily management service includes: resource pool management, teaching management, and system management. Resource pool management contains media pool management, namely the edition of multi-media and data, which can also contain the management of item pool, course, and examples and so on. Teaching management includes teacher management, student management, school roll management, educational administration management, learning management, test management, etc. while system management includes safety management, performance management, accounting management, and fault management and so on [6]. 


\subsection{Development Phase}

Our school has purchased the class Dream Factory of Beijing Vellcom Technology Co., Ltd and ChinaEDU CPT2.2 in Beijing. These two network course development platforms make the most of component technology [7], with which teachers can edit resources neatly because of its easy operation. Once network course needs a lot of change, the maker could edit it again.

On the process of making network course, teachers should pay attention to the follow points:

(a) The preparation of materials. On the making of PPT taped lecture for the video, the format should be confirmed. In view of former reasonable experience, this paper suggests that the default font, color, size should be planed, as well as how to arrange the layout of chapters, how to show key point, how to distinguish between theory and practical application, etc. It is better to avoid nonessential time waste as far as possible. In the test system, examination questions are designed and arranged according to the character of its course. Each test paper which provides answers is kept utility. Time should be distributed reasonably in the process of making the video, so as to make sure every teacher could teach each class well. In the communication tools system, the tools can be integrated into network course by linking fully-fledged programs in the net, such as BBS, E-mail, guest book, chat room, electron plate and on-line conference, etc. Other materials are prepared by following certain standard which has defined in demand analysis in the same way.

(b) The edition of columns and chapters in CPT and the uploading of resources. First, the maker can be familiar with the platform interface operation by reading its instruction booklet. Then, specific columns are done as requested, for example: course homepage, learning guide, teaching program, test program, simulation test, literature cite, course resources, interaction exchange, virtual experiment and counseling Q/A, etc. Next, specific chapters are done whose hiberarchy should be planed reasonably. Those relative resources are uploaded in accordance with columns which are prepared at first, but not the video. They are packed and saved in the hard disk.

(c) The edition of video in the Dream Factory. When teachers have transcribed the video, its head or tail may appear some bad effect unavoidably, which can be solved by Dream Factory through cutting those not ideal parts.

(d) The integration of these two sets of platforms. The process will be involved in the following Case Analysis.

\subsection{Examination, Payment and Maintenance Phase}

Software test is extremely important. After finishing software development, test is essentially. What's more, "Carry on the software test as soon as possible and unceasingly" can be regarded as the software developer's motto. In the network course test, some essential materials and concrete details should be checked based on 
their standard. Furthermore, the integrated whole network course should run in computer platform in order to judge if it is normal.

In the payment phase, certain interactive method like reader mailbox can be opened up to obtain some opinion about improvement of network course. After the probationary period, the daily running and maintenance is kept on. However, it doesn't mean that a project has been completed thoroughly. A real qualified network course isn't a once develop, benefiting from all life. Now it needs updating frequently in daily maintenance along with new knowledge appears unceasingly, and make sure its advanced nature.

\section{CASE ANALYSIS: THE DESIGN OF NETWORK COURSE}

Here the concrete making process of network course will be introduced. After installing CPT software, the maker lands to the assigned service, which appears an interface as Figure 4. The operation of its interface is simple, one could edit network course structure under the course structure window by following its operation instructions handbook.

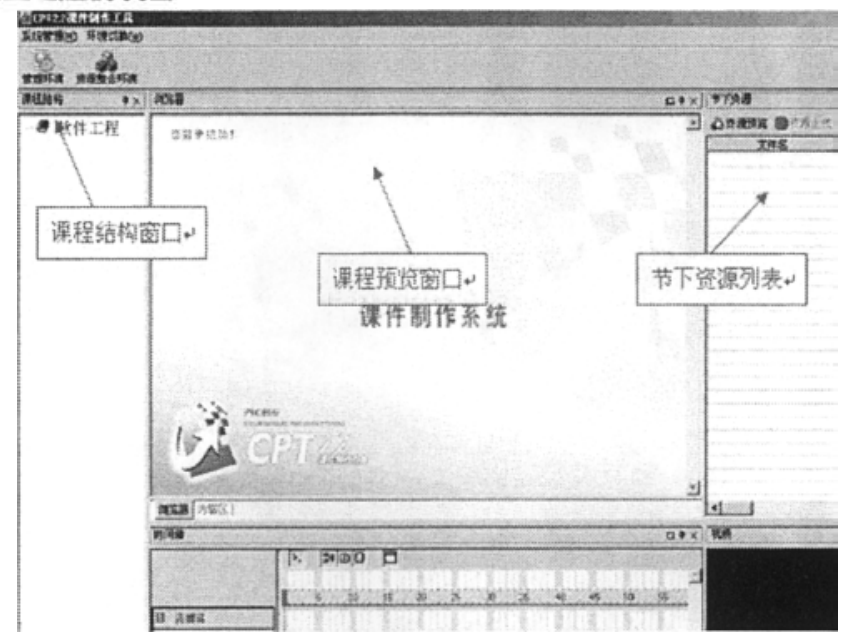

Figure 4. The Interface of CPT

Firstly, the course name of "software engineering" can be seen in the course structure window. The next step is clicking on the right key; choosing the course template; and uploading the home page picture. When pressing the right key on the course name, sub-menu will be seen. According to sub-menu, the relative chapters and columns could be established easily. Similar operation is repeated until all of the directory frames are established. Then, in the section resource list, one can click "resource upload", and a window will jump out with some hints says: "upload some relative contents." We do it. Corresponding resource information can be previewed in the course preview window by the way of clicking a resource. 


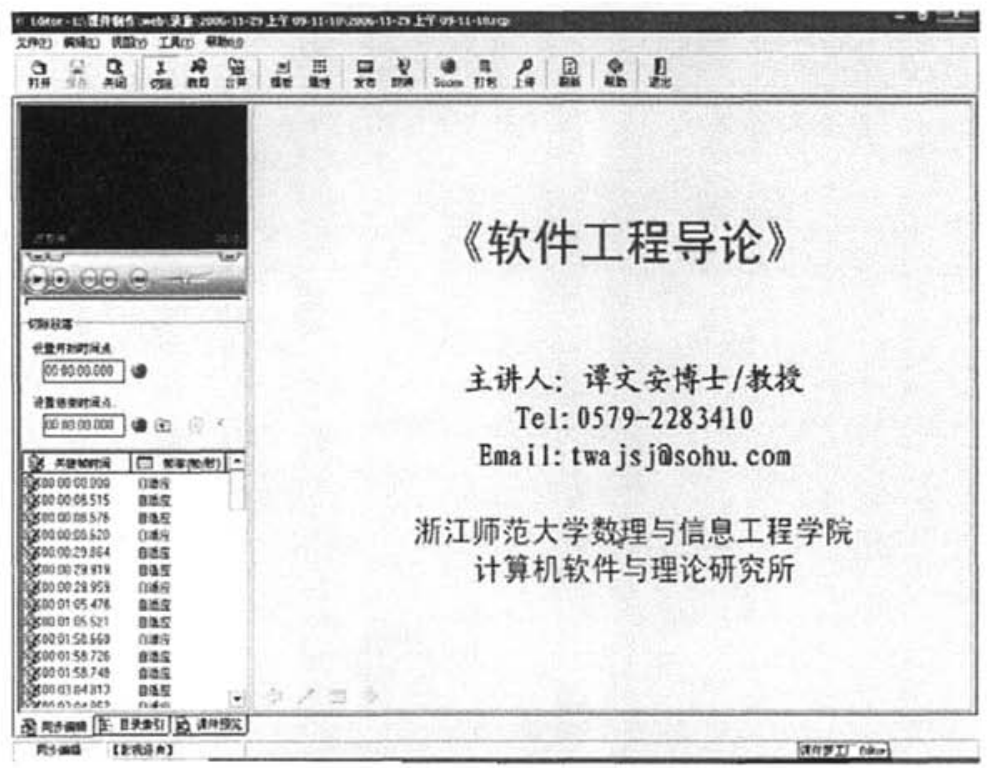

Figure 5. The Video Interface of Network Course

After all of these resources have been added repeatedly, we pack it. The next step is making the video. Firstly the video REC should be made, after teacher transcribing all chapters, it is edited by Dream Factory. Parts of pretreatment shows like Figure 5.

Now we open the video which has already transcribed, set the start and end time point, and cut the nonessential video. When all the videos have edited, the aforementioned two semi-finished products of CPT need to be integrated with Dream Factory as following steps [8], to form network course.

- The content issuing must be finished first when the synchronized content has been done by Dream Factory. The issued content network course is saved under the folder of its release directory (In the following it is called Release Directory for short).

- Then the modules developed from the template file, namely as "index.html" and picture, should be copied to Release Directory.

- Next is to issue the course structure and course columns finished in CPT, whose content is stored as a form of compression package in local hard disk.

- The compression package of CPT needs to be decompressed to the hard disk. The decompression directory is regarded as the main directory of the whole course. The file of default.html can be seen in the main directory, which is home page of the course.

- Now, we can open the file named as "framework.xml" in the subdirectory of the main directory using notepad and replace the information of one line whose context is "../content/kcjj/ch_??/se_??/timeline.html" with “../content/kcjj/ch_??/se_??/index.html”. 
- All the contents which are in the directory named as Release Directory are copied into the subdirectory of the corresponding chapter which is in main directory. The concrete path is named as "content/kcjj/ch_??/se_??".

- At last, we can open the home page of this course and preview the product.

\section{CONCLUSIONS AND PERSPECTIVES}

The construction of network course is a kind of software engineering. Therefore, we must strictly treat each phase of network course development. The maker should attach importance to the demand analysis, confirm every document in the development, realize software configuration management as well as implement the concrete content of network course following certain standard strictly. At the same time, by using the component technology of software development and utilizing the existed mature develop platform, we can easily address issues appeared in one-off developed course, such as updating difficult, expanding impossible, and nonrenewable, etc. This approach to network course can also enable the network course in batch processing, which is suitable for modern network education.

\section{ACKNOWLEDGEMENTS}

This work was supported by the project, namely software engineering, network course in Zhejiang Normal University.

\section{REFERENCES:}

1. J.P. Zhang, Modern Education Technology: Theory and Practice (High Education Publishing House: Beijing, 2003).

2. N. Li and F. Zhou, Research and Exploration about Network Course Construction, China Audiovisual Education. Number 221, pp.78-80, (2005).

3. R. Zheng, R. Yin, and Y. Tao, Practical Software Engineering (Tsinghua University Publishing House: Beijing, 1997).

4. W. Zhang, Software Engineering (Higher Education Publishing House: Beijing, 2001)

5. X. Yu and X. Shi, The Deliberation and Practice of Network Course Construction. Journal of Technology College Education. Volume 25, Number 1, pp.88-90, (2006).

6. Modern Distance Education Resources Construction Technological Specification, Ministry of Education, Modern Distance Education Resources Construction Committee, (2000).

7. Z. Wang, Y. Fei, and Y. Lou, Software Component Technology and its Application (Scientific Publishing House: Beijing, 2005)

8. The Integration Method of Two Set of Network Course Develop Platform, Zhejiang Normal University Adult Education Institute (2006).

9. http://cjy.zjnu.net.cn/list.asp?unid $=809$ 